\title{
Diet supplementation with cholesterol and vitamin E influences rat hormonal and immune status*
}

\author{
B. Sińska ${ }^{1}$, B. Sotowska ${ }^{2}$, D. Rosołowska-Huszcz ${ }^{2}$, M. Markowska ${ }^{3}$, \\ M. Bożentowicz ${ }^{3}$, K. Skwarło-Sońta ${ }^{3}$ and J. Gromadzka-Ostrowska ${ }^{2,4}$ \\ ${ }^{1}$ Human Nutrition Department, Medical University \\ E. Ciotka 27, 01-445 Warszawa, Poland \\ ${ }^{2}$ Department of Dietetics, Faculty of Human Nutrition and Consumer Sciences, \\ Warsaw Agricultural University \\ Nowoursynowska 159c, 02-766 Warsaw \\ ${ }^{3}$ Department of Animal Physiology, Faculty of Biology, Warsaw University \\ Miecznikowa 1, 02-096 Warsaw, Poland
}

(Received 22 August 2006; revised version 29 November 2006; accepted 2 February 2007)

\begin{abstract}
Diet composition may influence the activity of the HPA and HPT axes, which, in turn, modulates immune system function. The aim of the present study was to investigate the response of rat hormonal and immune parameters to feeding with a standard diet supplemented with cholesterol and vitamin E. The experiment was performed on Wistar rats fed for 6 weeks on a diet without supplementation, or the same diet enriched with cholesterol and/or vitamin E. Vitamin E supplementation caused a decrease in body weight gain and an increase in thyroid peroxidase activity as well as raised plasma concentrations of thyroid hormones and corticosterone. Supplementation with both cholesterol and vitamin $\mathrm{E}$ attenuated these effects. The cholesterol-enriched diet decreased plasma levels of ACTH while it stimulated the activity of $11 \beta$-hydroxylase deoxycorticosterone in the adrenals. Splenocyte proliferation in vitro was modified by the cholesterol-enriched diet but additional supplementation with vitamin $\mathrm{E}$ reversed these effects.
\end{abstract}

KEY WORDS: nutrition, vitamin E, cholesterol, HPA, HPT, immunity

\section{INTRODUCTION}

Control of the energy balance in an organism is continuously adjusted to the quantity and quality of the food intake. Different regulatory axes are involved,

\footnotetext{
* Supported by the Ministry of Scientific Research and Information Technology, Grant No. 3 P06T 02624

${ }^{4}$ Corresponding author: e-mail: joanna_gromadzka_ostrowska@sggw.pl
} 
not only in the maintenance of metabolic balance, but also the resultant humoral signals influence other physiological functions including immune system activity (Matarese and La Cava, 2004). Nutrition directly affects several aspects of both innate and adaptive immunity in humans and rodents (e.g., Chandra and Sarchielli, 1996) via modifications of immune cell plasma membrane composition and fluidity (Peck, 1994). The indirect influence of nutrients on immunity involving the neuroendocrine regulatory axes (e.g., Fabris, 1994) has been less frequently examined.

Among components of the diet, the level of cholesterol seems to be of great importance due to its numerous metabolic effects that often lead to pathological changes, e.g., neurological or cardiovascular disorders (Wolozin, 2002). Membrane cholesterol also plays a crucial role in the regulation of both intracellular transport and signaling pathways (for review see Pucadyil and Chattopadhayay, 2006). In particular, the effects of cholesterol on intracellular thyroid hormone uptake (Benvenga et al., 2002), and on T lymphocyte receptor (TCR)-mediated activity (Rouquette-Jazdanian et al., 2006) have been highlighted. Moreover, a highcholesterol diet has been shown to stimulate adrenal steroidogenesis (Abidi et al., 2004).

On the other hand, vitamin $\mathrm{E}$ is known to affect many physiological functions through its anti-proliferative, anti-oxidative and anti-inflammatory properties (Azzi et al., 2002; Brigelius-Flohe et al., 2002). Interactions between cholesterol and vitamin $\mathrm{E}$ have been demonstrated in studies on atherogenesis and oxidative stress (Brigelius-Flohe et al., 2002).

The present study was undertaken to investigate the complex regulatory network between dietary factors and endocrine and immune systems functions. The specific aim was to evaluate the effects exerted on homeostatic mechanisms by dietary supplementation with cholesterol and/or vitamin E. In rats fed a standard laboratory diet enriched with cholesterol and/or vitamin E, several parameters of the hypothalamo-pituitary-adrenal (HPA) and -thyroid (HPT) axes as well as immune system function were examined.

\section{MATERIAL AND METHODS}

\section{Experimental design}

The study was performed on 21 male Wistar rats of between body weight 190-200 $\mathrm{g}$ at the start of the experiment. Animals were kept in individual steel cages at $22 \pm 0.5^{\circ} \mathrm{C}$ under a $12: 12 \mathrm{~h}$ light:dark regime, with free access to feed and water. Body weight and feed intake were monitored weekly. All procedures were approved by the Local Animal Care and Use Committee in Warsaw. 
After one week of adaptation, animals were randomly assigned to four dietetic groups: 1. receiving the standard pelleted rat diet, Labofeed $\mathrm{H}$ containing $3.12 \%$ $(\mathrm{w} / \mathrm{w})$ of vegetable fat (basal), 2. standard diet supplemented with $3 \%(\mathrm{w} / \mathrm{w})$ cholesterol (Alchem, Poland) (Chol), 3. standard diet supplemented with $500 \mathrm{mg}$ vitamin E (Medana Pharma Terpol Group SA, Poland) per kg of diet (Vit. E), and 4. standard diet supplemented with $3 \%(\mathrm{w} / \mathrm{w})$ cholesterol and $500 \mathrm{mg}$ vitamin $\mathrm{E}$ per $\mathrm{kg}$ of diet (Chol/Vit. E). The composition of the standard Labofeed $\mathrm{H}$ pellets (Gronowska-Senger and Pierzynowska, 2002) and its fatty acid content estimated by gas chromatography (Daniewski et al., 2003) are shown in Tables 1 and 2.

Table 1. The composition of the standard pellets Labofeed $\mathrm{H}$ in experimental dietary groups estimated according to Gronowska-Senger and Pierzynowska (2002), g/100 g of diet

\begin{tabular}{|c|c|c|c|c|}
\hline Protein & Fat & Carbohydrates & Ash & Dry matter \\
\hline $24.9-25.5$ & $3.12-6.14^{1}$ & $52.24-54.78$ & $4.52-4.68$ & $87.9-88.1$ \\
\hline \multicolumn{2}{|c|}{ Energy, $\mathrm{kJ} / \mathrm{g}$ of diet } & & $14.7-15.3$ & \\
\hline \multicolumn{5}{|c|}{$\%$ energy supplied } \\
\hline protein & & & $27.44-29.20$ & \\
\hline fat & & & $8.04-15.14^{1}$ & \\
\hline carbohydr & & & $57.65-62.76$ & \\
\hline
\end{tabular}

1 - diets supplemented with $3 \%(\mathrm{w} / \mathrm{w})$ cholesterol

vitamin $\mathrm{E}$ content in pellets $-60 \mathrm{mg} / \mathrm{kg}$ of diet

Table 2 . Fatty acid content (\%) estimated by gas chromatography analysis in standard pellets Labofeed $\mathrm{H}$

\begin{tabular}{lc}
\hline Fatty acids & $\%$ \\
\hline SAFA & 17.64 \\
(mainly 16:0) & $(13.01)$ \\
MUFA & 21.67 \\
(mainly 18:1 cis) & $(19.56)$ \\
PUFA & 57.41 \\
(mainly 18:2 cis) & $(40.81)$ \\
PUFA/SAFA ratio & 3.25 \\
MUFA/SAFA ratio & 1.23 \\
Unsaturated/saturated ratio & 4.48 \\
\hline
\end{tabular}

After 6 weeks of feeding, rats were anesthetized and sacrificed by cardiac puncture. The adrenal and thyroid glands were dissected out, rinsed in saline, weighed, immediately frozen in liquid nitrogen and stored at $-80^{\circ} \mathrm{C}$ until further examination. Blood plasma was stored at $-23^{\circ} \mathrm{C}$ before analysis. Spleens were removed aseptically into minimal essential medium (MEM, Polfa, Lublin, Poland) and immediately used for preparing cell cultures in vitro. 
Analysis

Plasma lipids. Plasma lipid concentrations (total cholesterol - TC, high density lipoprotein fraction - HDL, phospholipids - PL and triacylglycerols - TG) were measured using enzymatic kits (BioMérieux, Marcy-l'Etoile, France).

Plasma hormone concentrations. Plasma concentrations of adreno-corticotropic hormone (ACTH), corticosterone (CS), thyrotropin (TSH), triiodothyronine (T3)

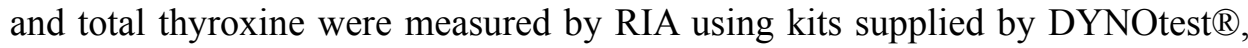
BRAMS, (USA); DSL-80100 Diagnostic Systems Laboratories, Inc. (USA); Biocode (Belgium), and Polatom (Warsaw, Poland), respectively. The highly specific antibodies used showed no cross-reaction with other polypeptides and steroid hormones, respectively. Inter- and intra-assay coefficients of variation (CVs) were $<8.4 \%$ for all assays.

Adrenal 11 $\beta$-hydroxylase deoxycorticosterone (11 $\beta O H-D C)$ activity. Activity of $11 \beta \mathrm{OH}-\mathrm{DC}$ was assayed as described by Lo et al. (1998) with slight modifications. Conversion of ${ }^{14} \mathrm{C}$-deoxycorticosterone (DOC) to ${ }^{14} \mathrm{C}$-CS in paired whole adrenal homogenates during $120 \mathrm{~min}$ of incubation at $37^{\circ} \mathrm{C}$ was expressed as percent conversion of ${ }^{14} \mathrm{C}$-DOC to ${ }^{14} \mathrm{C}-\mathrm{CS}$ per $\mathrm{mg}$ of adrenal homogenate protein measured by the method of Lowry et al. (1952).

Thyroid peroxidase (TPO) activity. Thyroid peroxidase activity was determined in the thyroidal microsomal fraction as described previously (Rosołowska-Huszcz, 1998). The amount of enzyme giving a change of 0.001 absorbance units per sec was defined as 1 unit.

Splenocyte proliferation in vitro. Splenocyte cultures in vitro were prepared according to a method established in our laboratory for rat lymphocytes, as described previously (Bik et al., 2006). Splenocytes were cultured in 96-well tissue culture plates $\left(2.5 \times 10^{5}\right.$ cells/well $)$ in the presence of serial dilutions of the T-cell mitogen phytohaemagglutinin (PHA; 0.5, 1.0, $2.0 \mu \mathrm{g} / \mathrm{well}$ ) or the B-cell mitogen lipopolysaccharide (LPS; 1.5, 3.0, $6.0 \mu \mathrm{g} / \mathrm{well})$. Control cultures were incubated with the culture medium alone (spontaneous proliferation). Cells were incubated for $72 \mathrm{~h}$ at $37^{\circ} \mathrm{C}$ in a fully humidified $5 \% \mathrm{CO}_{2}$ atmosphere. Prior to harvesting with a semiautomatic cell harvester (Skatron), the splenocytes were pulsed for $18 \mathrm{~h}$ with $1 \mu \mathrm{Ci} /$ well of $\left[{ }^{3} \mathrm{H}\right]$-thymidine. Incorporated radioactivity was measured in a liquid scintillation counter (Beckman) and expressed in cpm or as the stimulation index (SI; cpm in mitogen-stimulated culture divided by $\mathrm{cpm}$ in control culture).

\section{Statistical analysis}

Statistical analysis was performed using the least significant difference test for all but the immune parameters, which were analysed by the Student-Newman- 
Keuls test. Differences were considered statistically significant when $\mathrm{P} \leq 0.05$. Values on figures are expressed as means $\pm \mathrm{SE}$.

\section{RESULTS}

\section{Body weight gain and feed intake}

In rats receiving the diet Vit. E, the body weight gain was significantly lower than in those fed the basal diet $(\mathrm{P}<0.01)$ or the diet $\mathrm{Chol} / \mathrm{Vit}$. $\mathrm{E}(\mathrm{P}<0.013)$. Feed intake did not differ significantly between groups.

Table 3. Body weight gain and feed intake of rats fed standard diet nonsupplemented (basal) or enriched with cholesterol (Chol), vitamin E (Vit. E) or both (Chol/Vit. E); mean (SEM). Values with the same superscripts differ significantly

\begin{tabular}{lcc}
\hline Group & $\begin{array}{c}\text { Body weight gain } \\
\text { g/day }\end{array}$ & $\begin{array}{c}\text { Feed intake } \\
\text { g/day }\end{array}$ \\
\hline Basal & $3.86(0.31)^{\mathrm{a}}$ & $25.45(1.95)$ \\
Cholesterol & $3.94(0.16)$ & $27.79(1.34)$ \\
Vitamin E & $2.90(0.24)^{\mathrm{a}, \mathrm{b}}$ & $24.87(0.71)$ \\
Chol/Vit. E & $3.90(0.36)^{\mathrm{b}}$ & $24.52(1.26)$ \\
\hline
\end{tabular}

\section{Plasma lipids}

Total plasma cholesterol concentration was higher in rats fed the Chol and $\mathrm{Chol} / \mathrm{Vit}$. E diets, while it was decreased by supplementation with vitamin $\mathrm{E}$ alone $(\mathrm{P} \leq 0.05)$. Total plasma TG concentration was not influenced by the Chol or Chol/ Vit. E diets, whereas vitamin E supplementation caused a significantly lower TG level $(\mathrm{P} \leq 0.001)$. In contrast, supplementation with vitamin $\mathrm{E}$ produced a very large increase in the HDL cholesterol fraction $(\mathrm{P} \leq 0.0001)$.

\section{Pituitary-adrenal axis activity}

Plasma ACTH concentration was significantly lower $(\mathrm{P} \leq 0.05)$ in rats fed Chol compared with the basal diet and was not influenced by additional supplementation with vitamin E. Adrenal $11 \beta \mathrm{OH}-\mathrm{DC}$ activity was increased by the Chol diet $(\mathrm{P} \leq 0.05)$, while the effect caused by additional supplementation with vitamin $\mathrm{E}$ was not statistically significant. Unfortunately, for both of the above parameters the results from the group fed the diet supplemented with vitamin $\mathrm{E}$ alone are lacking. The plasma CS concentration was significantly higher in animals fed the 
A
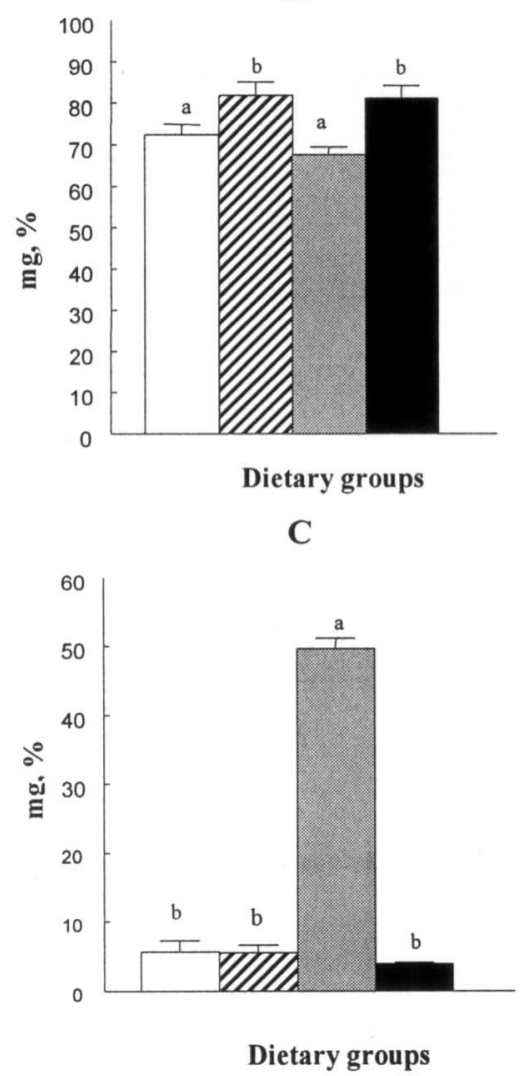

B

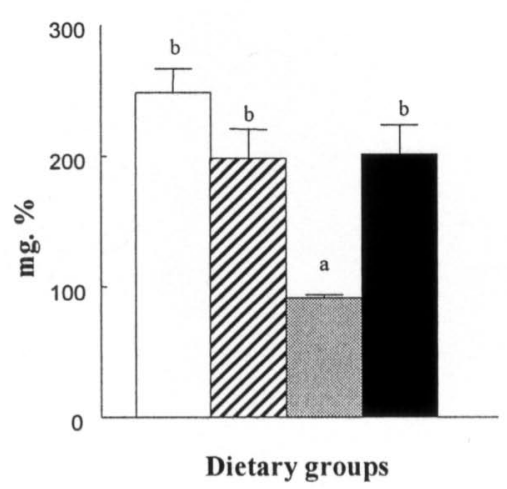

Figure 1. Total cholesterol (A), triacyloglicerols (B) and HDL cholesterol (C) plasma concentration examined after 6 weeks of feeding rats with: $\square 1$ - basal, $\mathscr{Z} 2$ - enriched with $3 \%$ of cholesterol (Chol), $\square 3$-enriched with $500 \mathrm{mg} / \mathrm{kg}$ of diet vitamin E (Vit. E) or $\mathbf{\square}$ - both (Chol/ Vit. E) diets (mean $\pm \mathrm{SE}$ ). Letters above bars indicate statistically significant differences

Vit. E diet compared with the other groups $(\mathrm{P} \leq 0.05)$. The Chol and Chol/Vit. E diets did not influence plasma CS concentration.

\section{Pituitary-thyroid axis activity}

Enrichment of the diet with vitamin $\mathrm{E}$ alone increased TPO activity $(\mathrm{P} \leq 0.02)$ and raised plasma T4 $(\mathrm{P} \leq 0.001)$ and T3 $(\mathrm{P} \leq 0.00001)$ levels. Supplementation with cholesterol alone produced no significant changes in either TPO activity or plasma T4 and T3 concentrations, but it attenuated the effect of vitamin E on these parameters. TSH level was not significantly affected by cholesterol and/or vitamin E supplementation. 

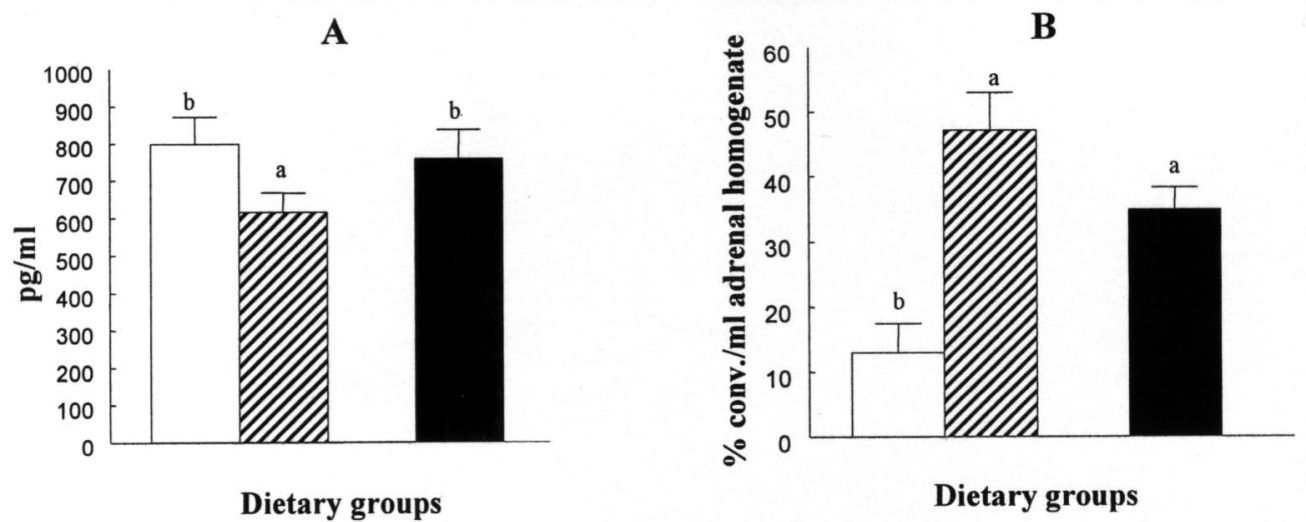

Dietary groups

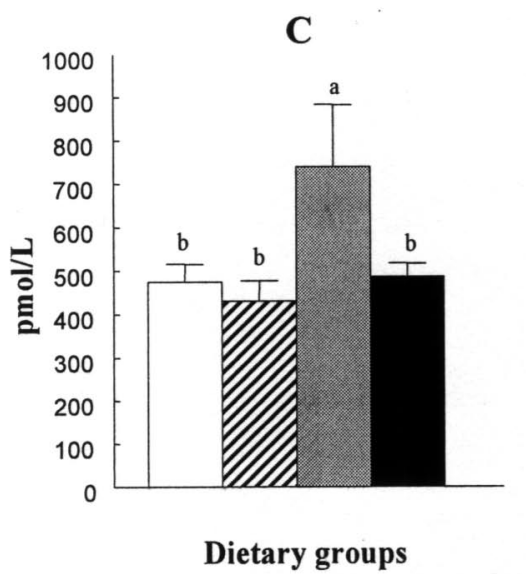

Figure 2. Plasma ACTH concentration (A), 11ß-hydroxylase deoxycorticosterone adrenal activity (B) $\left(\%\right.$ conversion of ${ }^{14} \mathrm{C}-\mathrm{DOC}$ to $\left.{ }^{14} \mathrm{C}-\mathrm{Cs} / \mathrm{ml}\right)$ and plasma corticosterone concentration $(\mathrm{C})$ in rats (mean $\pm \mathrm{SE}$ ). Explanations as in Figure 1

\section{Splenocyte proliferation}

Spontaneous proliferation of splenocytes was decreased by dietary supplementation with cholesterol $(\mathrm{P} \leq 0.001)$, and addition of vitamin $\mathrm{E}$ reversed this effect $(\mathrm{P} \leq 0.001)$. Splenocytes from both basal and Chol groups did not respond to PHA, which was an efficient $(\mathrm{P} \leq 0.001)$ stimulant of cells from group $\mathrm{Chol} /$ Vit. E. On the contrary, splenocytes from both basal and Chol dietary group were stimulated by LPS, and Chol diet potentiated the stimulation but after vitamin $\mathrm{E}$ addition to the diet, splenocytes failed to respond to this mitogen.

Results regarding the in vitro proliferation of splenocytes from the Vit. E group are unfortunately lacking. Figure $4 \mathrm{~B}$ and $4 \mathrm{C}$ show the SI values obtained with only 


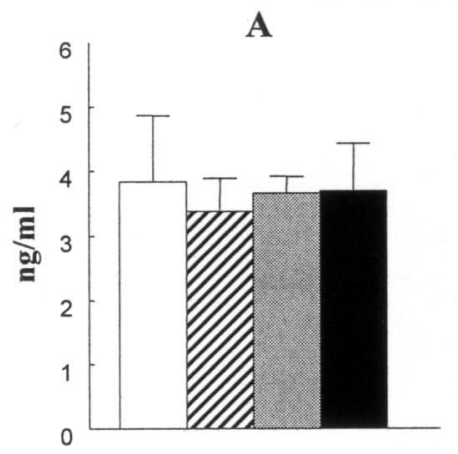

Dietary groups

C

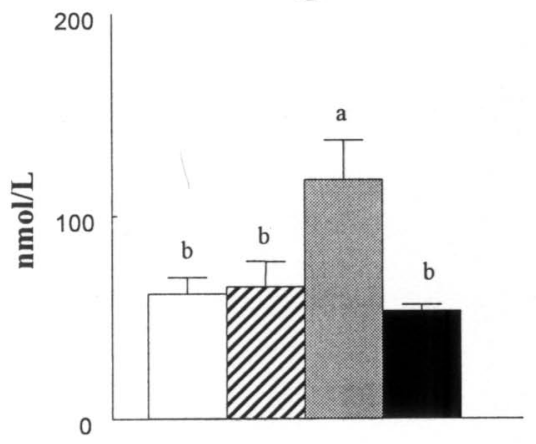

Dietary groups

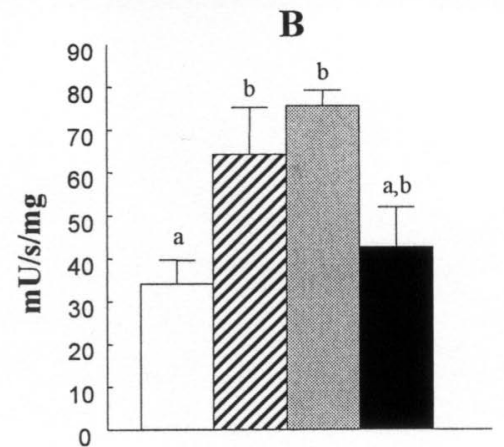

Dietary groups

D

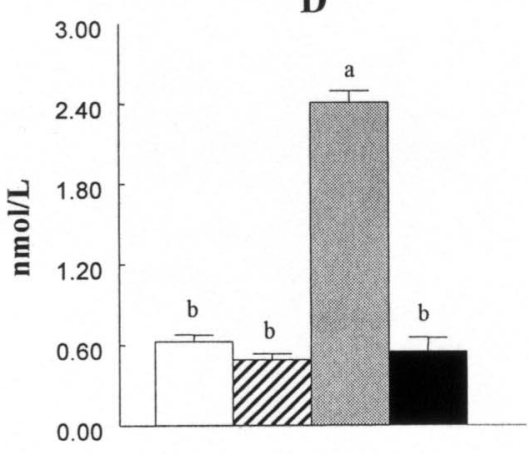

Dietary groups

Figure 3. Plasma TSH concentration (A), TPO activity (B), and plasma T4 (C) and T3 (D) concentration in rats (mean $\pm \mathrm{SE}$ ). Explanations as in Figure 1

one of the mitogen concentrations used ( $2 \mu \mathrm{g} / \mathrm{well}$ of PHA and $6 \mu \mathrm{g} / \mathrm{well}$ of LPS), because in all cases the response was dose-dependent. Similarly, when the cells failed to respond, this was the case regardless of the mitogen concentration applied.

\section{DISCUSSION}

The various dietary regimes administered in this study produced different effects on the parameters examined. Body weight gain was diminished in rats receiving vitamin E supplementation, as has been observed previously (Al-Shamsi et al., 2004). This does not seem to be related to the level of feed intake, which was comparable in all groups. Addition of cholesterol to the vitamin E-rich diet negated its effect on body weight gain. The lower body weight gain in the Vit. E group corresponded to 
A

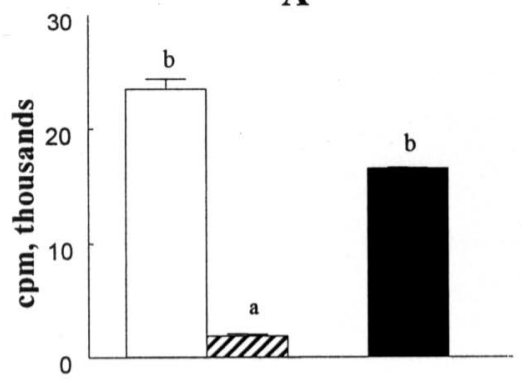

Dietary groups
B

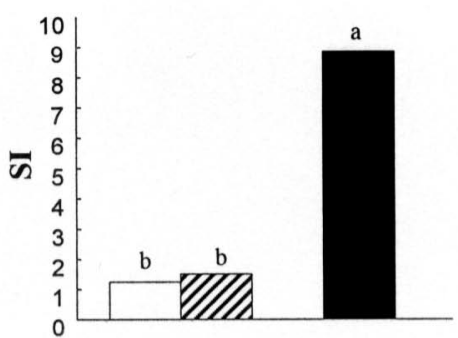

Dietary groups

C

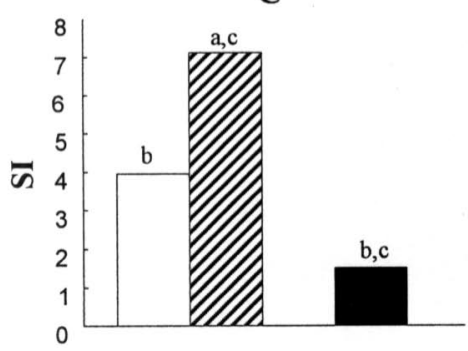

Dietary groups

Figure 4. Spontaneous (A) (mean \pm SE), PHA activated (B) and LPS activated (C) splenocyte proliferation in rats. Explanations as in Figure 1

higher values of thyroid activity indices: TPO activity and plasma T4 and T3 levels. This suggests that the lower body weight gain was due to a raised metabolic rate in this group. The increased thyroid activity in the Vit. E group could also account for the lower total cholesterol levels and higher HDL fraction.

To date, few studies have addressed the influence of vitamin $E$ on thyroid activity. Vitamin $\mathrm{E}$ has been found to have anti-goitrogenic and anti-proliferative effects in thyroid follicular cells (Oner et al., 2003). Epidemiological studies revealed significantly lower plasma vitamin $\mathrm{E}$ concentrations in children with enlarged thyroids (Mesaros-Kanjski et al., 1999). In our study, rats fed the Vit. E diet had a lower thyroid index than those from the Chol/Vit. E group (data not shown). This anti-proliferative effect of vitamin $\mathrm{E}$ has been suggested to be independent of its antioxidative activity and to be due to the inhibition of protein kinase $\mathrm{C}$ (Oner et al., 2003). The attenuation by cholesterol of the effects exerted by vitamin $E$ implies that these two factors may share common points of action, for example at the level of cell membranes. The effect of cholesterol alone on parameters of thyroid activity 
was not observed in our experiments. However, its influence on transmembraneous transport of thyroid hormones has been demonstrated (Benvenga et al., 2002). The decrease in plasma T4 and T3 observed in rats receiving joint supplementation of vitamin $\mathrm{E}$ and cholesterol could be due to such an effect.

Vitamin E supplementation also significantly increased the plasma CS concentration. This is the opposite of the effect of vitamin $E$ seen in stressed rats (Tsiakitzis et al., 2005). It may be assumed, therefore, that the effect of vitamin $\mathrm{E}$ on the HPA axis depends on its activity. Unfortunately, the incompleteness of our results prevented analysis of the effect of supplementation with vitamin E alone on ACTH plasma levels and adrenal 11ßOH-DC activity. Both of these indices were distinctly affected by elevation of cholesterol in the diet, but in an opposite manner, i.e. lower ACTH in the Chol group corresponded to higher 11ßOH-DC activity. The method used to estimate ACTH activity involved the exogenous supply of substrate and coenzyme, and so the values obtained directly reflect the amount of enzymatically active protein. Considering the previous finding that $11 \beta \mathrm{OH}-\mathrm{DC}$ gene expression is in fact stimulated by ACTH (Wang et al., 2000), we presume that the observed enzyme activity results from earlier stimulation.

It has recently been proposed that cholesterol homeostasis in the adrenals is regulated by liver X receptors (LXR) liganded by oxysterols (Cummins et al., 2006). This mechanism is believed to limit the activity of the steroidogenic pathway by preventing expression of the steroidogenic protein (StAR) gene while simultaneously inducing $\mathrm{ABC}$ transporters mediating cholesterol efflux. In this manner, the rate of steroidogenesis seems to be protected from exaggerated cholesterol supply.

In the present study, the relatively weak effect exerted on the HPA and HPT axes by dietary supplementation with cholesterol alone, was surprisingly accompanied by changes in the ability of immune cells to proliferate in vitro-abasal parameter of immune system function. Spontaneous proliferation of splenocytes that was significantly diminished by consumption of the diet enriched in cholesterol (similar to the changes observed in the elderly) was re-established by additional diet supplementation with vitamin E. Similar vitamin E-induced enhancement of immune function, involving various direct and indirect mechanisms, has been demonstrated previously (Meydani et al., 2005). Furthermore, B-cells of rats fed the basal diet responded to mitogenic (LPS) stimulation relatively well, which was potentiated in the Chol group. This result is in accord with the well accepted involvement of cholesterol in lipid rafts, where it stabilizes plasma membrane structure and facilitates signal transduction by immune cells (Van der Goot and Harder, 2001). The mechanism by which additional dietary supplementation with vitamin $\mathrm{E}$ reverses this effect, as with its aforementioned influence on thyroid gland activity, requires further investigation.

The influence of dietary supplementation on splenocyte responses to PHA, a T-cell mitogen, was quite different. Cells obtained from both basal and Chol 
groups were unable to respond to PHA, but following additional supplementation of the diet with vitamin $\mathrm{E}$, the cells became responsive to stimulation. A similar improvement in T-cell mitogen-stimulated proliferation was recently demonstrated in mice fed a diet enriched with different antioxidants including vitamin $\mathrm{E}$ (Alvarado et al., 2005); this was interpreted as evidence that the correct oxidantantioxidant balance is critical for immune cell function.

The modifications of immune cell activity demonstrated in our experiments seem, at least partly, to be connected with hormonal status. Rats fed the basal diet exhibited relatively high plasma ACTH concentrations (not correlated, however, with adrenal synthesis and plasma level of CS) together with relatively low values for HPT axis parameters (TPO activity, plasma T3 and T4 concentrations). The dependence of immune system function on stress hormones and thyroid gland activity is well documented (Silberman et al., 2002), but so far, to our knowledge, it has not been correlated with nutritional status. It is difficult to explain the immunomodulatory effects exerted by dietary vitamin E supplementation (inhibiting B- and stimulating T-cell proliferation in vitro), but in both cases it antagonized the effects of the diet rich in cholesterol. Apart from its well known protective effect on lipid peroxidation (Alvarado et al., 2005), vitamin E could also influence the synthesis of specific cytokines involved in lymphocyte proliferation (Venkatraman and Chu, 1999).

To summarize, the results presented in this study clearly demonstrate that in rats, a diet rich in cholesterol and/or vitamin $\mathrm{E}$ influences both hormonal and immune homeostasis. These effects might be exerted directly on the biosynthetic activity of endocrine glands and on immune cell signaling, dependent most probably on plasma membrane fluidity. Immune functions may also be modulated indirectly, through diet-induced changes in the hormonal status of the animal.

\section{REFERENCES}

Abidi P., Leers-Sucheta S., Azhar S., 2003. Suppression of steroidogenesis and activator protein-1 transcription factor activity in rat adrenals by vitamin $\mathrm{E}$ deficiency-indiced chronic oxidative stress. J. Nutr. Biochem. 15, 210-219

Al Shamsi A.A., Adeghate E., 2004. Beneficiail effect of vitamin E on metabolic parameters of diabetic rats. Mol. Cell. Biochem. 261, 35-42

Alvarado C., Alvarez P., Jimenez L., De La Fuente M., 2005. Improvement of leukocyte functions in young prematurely aging mice after 5-week ingestion of a diet supplemented with biscuits enriched in antioxidants. Antioxid. Redox Signal. 7, 1203-1210

Azzi A., Ricciarelli R., Zingg J.M., 2002. Non-antioxidant molecular functions of $\alpha$-tocopherol (vitamin E). FEBS Lett. 519, 8-10

Benvenga S., Alesci S., Trimarchi F., 2002. High-density lipoprotein-facilitated entry of thyroid hormones into cells: a mechanism different from the low-density lipoprotein-facilitated entry. Thyroid 12, 547-556 
Bik W., Wolińska-Witort E., Pawlak J., Skwarło-Sońta K., Chmielowska M., Martyńska L., Baranowska-Bik A., Baranowska B., 2006. PACAP 38 as a modulator of immune and endocrine responses during LPS-induced acute inflammation in rats. J. Neuroimmunol. 177, 76-84

Brigelius-Flohe R., Kelly F.J., Salonen J.T., Neuzil J., Zingg J.M., Azzi A., 2002. The European perspective on vitamin E: current knowledge and future research. Amer. J. Clin. Nutr. 76, 703-716

Chandra R.K., Sarchielli P., 1996. Body size and immune response. Nurt. Res. 16, 1813-1819

Chehin R.N., Rintoul M.R., Morero R.D., Farias R.N., 1995. Differential effect of triiodothyronine and thyroxine on liposomes containing cholesterol: physiological speculations. J. Membrane Biol. $147,217-221$

Cummins C.L., Volle D.H., McDonald J.G., Sion B., Lefrancois-Martinez A.M., Caira F., Veyssiere G., 2006. Liver X receptors regulate adrenal cholesterol balance. J. Clin. Invest. 116, 1902-1912

Daniewski M., Jacórzyński B., Filipek A., Balas J., Pawlicka M., Mielniczuk E., 2003. Fatty acids content in selected edible oils (in Polish). Rocz. PZH 54 (3), 263-267

Fabris N., 1994. Neuroendocrine regulation of immunity. Adv. Pineal Res. 7, 41-56

Gronowska-Senger A., Pierzynowska J., 2002. Biological Food Estimation. Exercises (in Polish). SGGW, Warszawa (Editor)

Lo M.J., Ksu M.M., Chen Y.H., Tai S.C., Chiao Y.C., 1998. Acute effects of thyroid hormones on the production cAMP and corticosterone in male rats. Amer. J. Physiol. 274, E238-E245

Lowry O.H., Rosenbrough N.J., Favy A.L., Randall O.P., 1951. Protein measurement with the Folin phenol reagent. J. Biol. Chem. 193, 265-275

Matarese G., La Cava A., 2004. The intricate interface between immune system and metabolism. Trends Immunol. 25, 193-200

Mesaros-Kanjski E., Kontosic I., Kusic Z., Kaick-Rak A., Dakovic N., Kuser J., Antonic K., 1999. Endemic goitre and plasmatic levels of vitamins $\mathrm{A}$ and $\mathrm{E}$ in the school-children on the island of Krk. Croatia. Collegium Antropol. 23, 729-736

Meydani S.N., Han S.N., Wu D., 2005. Vitamin E and immune response in the aged: molecular mechanisms and clinical implications. Immunol. Rev. 205, 269-284

Oner J., Kukner A., Oner H., Ozan E., Yekeler H., 2003. Effect of vitamin E on follicular cell proliferation and expression of apoptosis-associated factors in rats with 6-N-propyl-2-thiouracilinduced goitrogenesis. Folia Histochem. Cytobiol. 41, 213-217

Peck M.D., 1994. Interaction of lipids with immune function I: Biochemical effects of dietary lipids on plasma membranes. J. Nutr. Biochem. 5, 466-478

Pucadyil T.J., Chattopadhyay A., 2006. Role of cholesterol in the function and organization of Gprotein coupled receptors. Prog. Lipid Res. 45, 295-333

Rosołowska-Huszcz D., 1998. Effect of exercise training intensity on thyroid activity at rest. J. Physiol. Pharmacol. 49, 457-466

Rouquette-Jazdanian A.K., Pelassy C., Breittmayer J.P., Aussel C., 2006. Revaluation of the role of cholesterol in stabilizing rafts implicated in T cell receptor signaling. Cell. Signal. 18, 105-122

Silberman D.M., Wald M., Genaro A.M., 2002. Effect of chronic mild stress on lymphocyte proliferative response. Participation of serum thyroid hormones and corticosterone. Int. Immunopharmacol. 2, 487-497

Tsiakitzis K., Kourounakis A.P., Tani E., Rekka E.A., Kourounakis P.N., 2005. Stress and active oxygen species-effect of alpha-tocopherol on stress response. Arch. Pharmacol. 338, 315-321

Van Der Goot F., Harder T., 2001. Raft membrane domain: from lipid-ordered membrane phase to a site of patogen attack. Semin. Immunol. 13, 89-97

Venkatraman J.T., Chu W., 1999. Effects of dietary $\omega 3$ and $\omega 6$ lipids and vitamin E on proliferative response, lymphoid subsets, production of cytokines by spleen cells, and splenic protein levels for cytokines and oncogenes in MRL/MpJ-lpr/lpr mice. J. Nutr. Biochem. 10, 582-597

Wang X.L., Bassett M., Zhang Y., Yin S., Clyne C., White P.C., Rainey W.E., 2000. Transcriptional regulation of human 11beta-hydroxylase (hCYP11B1). Endocrinology 141, 3587-3594

Wolozin B., 2002. Cholesterol and Alzheimer's disease. Biochem. Soc. Trans. 30, 525-529 